\title{
Milk Peptide Intake May Decrease Muscle Damage after Eccentric Exercise
}

\author{
Norikazu Hirose $^{1}$, Maki Sato ${ }^{2}$, Osamu Yanagisawa ${ }^{3}$ and Toru Fukubayashi ${ }^{3}$ \\ ${ }^{1}$ Faculty of Sport Sciences, Waseda University; \\ 3-4-1 Higashifushimi Nishitokyo, Tokyo 202-0021, Japan \\ toitsu_hirose@waseda.jp \\ ${ }^{2}$ Nutritional Science Laboratory, Morinagamilk Milk Industry Co., Ltd.; \\ 5-1-83 Higashihara Zama, Kanagawa, 228-8583, Japan \\ ${ }^{3}$ Faculty of Sport Sciences, Waseda University; \\ 2-579-15 Mikajima Tokorozawa, Saitama 359-1192, Japan \\ [Received July 23, 2012; Accepted January 8, 2013; Published online January 19, 2013]
}

\begin{abstract}
The aim of this study was to examine the influence of milk peptide intake on the recovery from muscle damage following high-intensity eccentric exercise. To clarify this issue, we designed a cross over comparison study between peptide intake and control after eccentric calf raise exercise. Six healthy male volunteers (ranging from 19 to 22 years) performed high-intensity eccentric calf raise exercise. The CK, MRI T2 value of the calf were measured at pre-, post-, and on, day 1, 2, 3, 5 and 8 following the exercise to evaluate muscle damage as well as muscle soreness using a visual analog scale (VAS). Statistical differences in all measurements between the peptide and control condition were analyzed using two-factorial ANOVA. The peak value of each measurement between two trials was analyzed using the T-test. A statistical significance of $p<0.05$ was adopted.

The peak CK level $(p<0.05)$, MRI T2 value $(p<0.05)$, and VAS $(p<0.01)$ in the peptide condition were significantly lower than those in control. Although the mechanism of recovery from muscle damage is unclear, our finding suggests that milk peptide intake may be effective for decreasing muscle damage after high-intensity eccentric exercise.
\end{abstract}

Keywords: milk peptide, DOMS, CK, MRI

\section{Introduction}

Most athletes and people who participate in exercise programs have experienced delayed onset muscle soreness (DOMS) (Cheung et al., 2003). The main symptoms of DOMS are pain, impairment of range of joint motion, and decreased muscle strength (Nosaka and Clarkson, 1996). DOMS may be caused by the muscle damage that occurs following activities involving vigorous lengthening of muscles during eccentric exercise (Armstrong, 1984; Cleak and Eston, 1992). For measurement of DOMS, blood creatine kinase (CK) level (Nosaka and Clarkson, 1996) and magnetic resonance imaging (MRI) T2 value (LeBlanc et al., 1993; Nosaka and Clarkson, 1996; Clarkson and Hubal, 2002) have been adopted as indirect indicators. In addition, these indicators are also used as measures of pain, range of motion, and muscle strength.

DOMS and the associated impairment of muscle function because of muscle damage can decrease the ability to perform daily tasks and athletic activities (Cleak and Eston, 1992; Harrison and Gaffney, 2004; Twist and Eston, 2005). Therefore, effective prophylactic or therapeutic treatments must be identified to prevent or decrease DOMS and/or enhance recovery of muscle function after exercise. Various treatment strategies, including both physical interventions and pharmacological therapies, have been administered for prevention or reduction of DOMS and muscle damage and to enhance recovery from exercise-induced muscle damage (Howatson and van Someren, 2008). Although several nutritional supplement treatments have also been examined (Braun et al., 2005; Close et al., 2006; Cockburn et al., 2008; Etheridge et al., 2008; Lenn et al., 2002; Miller et al., 2004; Nosaka et al., 2006; Shimomura et al., 2006; White et al., 2008), the effectiveness of supplement intake has not been clearly demonstrated (Braun et al., 2005). However, some studies asserted 
the positive effect of nutritional supplementation on decreasing DOMS and muscle damage (Coombes and McNaughton, 2000; Kraemer et al., 2006; Sugita et al., 2003). For example, Nosaka et al. (2006) found that continuous intake of amino acids following endurance exercise decreased DOMS and muscle damage. Intake of protein sources before and after exercise may attenuate exercise-induced muscle protein breakdown and stimulate muscle protein synthesis.

As previously mentioned, amino acid supplementation may enhance recovery from muscle damage. In this study, we hypothesized that supplementation with milk peptides, which are hydrolyzed milk proteins, may attenuate muscle damage and DOMS because they provide a good source of protein and have excellent digestive and absorption qualities (Mikami et al., 1998). Milk peptides may therefore strengthen the positive effects of protein and amino acid intake.

This study aimed to determine whether intake of milk peptides decreased muscle damage and DOMS. Changes in blood CK level, MRI T2 value, and muscle soreness were measured following high-intensity eccentric exercise. In a crossover design study, these parameters were then compared in conditions with and without peptide intake.

\section{Methods}

\subsection{Subjects}

Six healthy untrained male volunteers (aged 19-22 years of age) participated in this study. Participants' mean height and body weight were $171.4 \pm 4.2 \mathrm{~cm}$ and $69.8 \pm 2.9 \mathrm{~kg}$ (means $\pm \mathrm{SE}$ ), respectively. All subjects were instructed to refrain from participating in any physical exercise for $48 \mathrm{~h}$ before the experimental exercise session. All subjects were fully informed about the procedures and the purposes of this study. Written informed consent was obtained from all participants. All study protocols were approved by the Human Ethics Review Committee of Waseda University.

\subsection{Experimental design}

A crossover comparison was performed between subjects who took milk peptide supplements (Pep) and those who did not take milk peptide supplements (Cont) (Figure 1). An interval of at least 8 weeks separated testing sessions. We selected 3 subjects randomly and they were subjected to the Cont condition after the Pep condition (Pep-Cont), while the other 3 subjects were subjected to the Pep condition after the Cont condition (Cont-Pep).

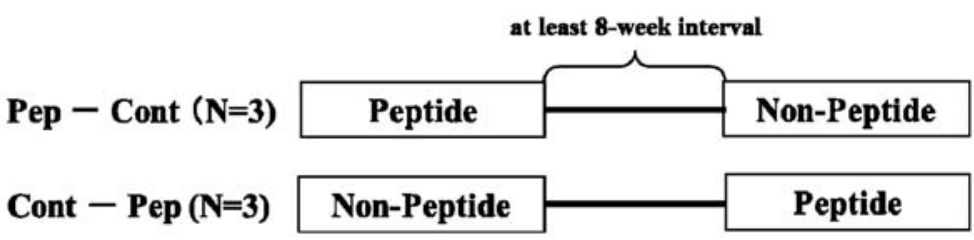

\begin{tabular}{|c|c|c|c|c|c|c|c|c|c|c|}
\hline \multirow{3}{*}{ Measurements } & \multicolumn{4}{|c|}{ Exercise day } & \multicolumn{6}{|c|}{ Days following the exerclse } \\
\hline & $-1 \mathrm{~h}$ & $\begin{array}{l}\text { Exercise } \\
\text { (Oh) }\end{array}$ & $\begin{array}{l}\text { Immediately } \\
\text { post- exercise }\end{array}$ & $12 \mathrm{~h}$ & 1-day & 2-day & 3-day & 4-day & 5-day & 8-day \\
\hline & & 0 & & & & & & & & \\
\hline CK & 0 & & 0 & & $\mathrm{O}$ & 0 & 0 & & 0 & 0 \\
\hline MRI & 0 & & & & 0 & 0 & 0 & & 0 & 0 \\
\hline Soreness & 0 & & \multicolumn{7}{|c|}{ O(every 12 hours from the night of the exercise to 5 days after exercise) } & $\mathrm{O}$ \\
\hline $\begin{array}{l}\text { Peptide intake } \\
\text { (only in the peptide trial) }\end{array}$ & 0 & & \multicolumn{7}{|c|}{ O(every 12 hours from the night of the exercise to 5 days after exercise) } & \\
\hline
\end{tabular}

Figure 1 Experimental design. Three subjects were initially assigned to the peptide intake (Pep) condition, after which they switched to the control condition (Cont). The other 3 subjects started with the control condition, after which they switched to the peptide intake condition. 


\subsection{Experimental protocol}

\subsubsection{Exercise conditions}

Muscle damage was induced in the bilateral calves as follows. Participants performed 5 sets of 15 repetitions of the calf-raise exercise on a stool to elicit full eccentric contractions of the triceps surae muscles with the bar on a Smith machine (Nautilus, Vancouver, WA, USA) across their shoulders. The load $(\mathrm{kg})$ was equal to each subject's body weight. Subjects were instructed to extend the ankle for $1 \mathrm{~s}$ (plantar flexion) and maintain that position for $1 \mathrm{~s}$ until returning to the start position at the 3-s mark. All exercises were performed using a metronome. In the last 5 repetitions of each set, the investigator aided as necessary in the concentric phase. Subjects were instructed to exert maximal effort during both the concentric and eccentric phases. A rest period of $60 \mathrm{~s}$ was allowed between exercise sets. During the rest period, participants were seated.

\subsubsection{DOMS measurement}

Muscle soreness was evaluated before and immediately after exercise, and every $12 \mathrm{~h}$ from the time of the exercise session to 5 days after using a visual analog scale (VAS). Subjects rated the level of soreness in the right calf on palpation and extension on a scale from 0 (no pain or soreness) to 10 (worst possible pain and soreness).

\subsubsection{Blood sample collection and analysis}

CK was measured prior to and immediately after exercise and on days $1,2,3,5$, and 8 following the exercise session. Whole blood samples were extracted from the index finger after cleaning with an alcohol-impregnated swab. A small puncture in the skin was made with an Autoclix lancet. Arterialized capillary blood samples $(30 \mu \mathrm{l})$ were collected in capillary tubes and then analyzed for plasma CK level using a Reflotron Plus biochemical analyzer (Roche Diagnostics K.K., Tokyo, Japan). This instrument was calibrated prior to use on every measurement day.

\subsubsection{MRI}

MRI of the calf was carried out using a 1.5-T MR system (SIGNA EXCITE XI, General Electric Co., Ltd., Fairfield, CT, USA) with the knee coil applied to subjects in the supine position $1 \mathrm{~h}$ before the exercise session and on days $1,2,3,5$, and 8 following the exercise session for evaluation of muscle damage. MRI was not performed immediately after exercise. The MR sequence was as follows: spinecho technique; repetition time $3,000 \mathrm{~ms}$; echo time $25,50,75$, and $100 \mathrm{~ms} ; 256 \cdot 160$ matrix; 1 excitation; 240-mm field of view; and $10-\mathrm{mm}$ slice thickness. The total scan time was $8.13 \mathrm{~min}$. The scan position was proximal to $75 \%$ of the length between the head of the fibula and the lateral malleolus on the right leg, that is, near the mid-calf.

For T2 calculations, the region of interest completely surrounded the medial gastrocnemius on MR images with an echo time of $25 \mathrm{~ms}$. The region of interest was copied onto each image with echo times of $50 \mathrm{~ms}, 75 \mathrm{~ms}$, or $100 \mathrm{~ms}$. T2 relaxation time was calculated by fitting the spectroscopic imaging at each echo time to a monoexponential decay using a leastsquares algorithm.

\subsubsection{Supplements}

The supplement intake included $5 \mathrm{~g}$ of milk peptide per pack. During the peptide trial, subjects took the supplement 13 times in the testing period: $1 \mathrm{~h}$ before and immediately after exercise, and twice a day

Table 1a Ingredients of the supplement

\begin{tabular}{ll}
\hline Ingredients (per pack) & \\
\hline Carbohydrate $(\mathrm{g})$ & 2.0 \\
\hline Fat $(\mathrm{g})$ & 0.0 \\
\hline Protein $(\mathrm{g})$ & 5.0 \\
\hline Sodium $(\mathrm{mg})$ & 57 \\
\hline Energy $(\mathrm{kcal})$ & 28 \\
\hline
\end{tabular}

Table 1b Amino acid composition of the supplement

\begin{tabular}{lc|lc}
\hline Isoleucine & $300 \mathrm{mg}$ & Valine & $350 \mathrm{mg}$ \\
\hline Leucine & $450 \mathrm{mg}$ & Histidine & $150 \mathrm{mg}$ \\
\hline Lysine & $445 \mathrm{mg}$ & Arginine & $165 \mathrm{mg}$ \\
\hline Methionine & $145 \mathrm{mg}$ & Alanine & $185 \mathrm{mg}$ \\
\hline Cysteine & $15 \mathrm{mg}$ & Asparagine & $450 \mathrm{mg}$ \\
\hline Phenylalanine & $200 \mathrm{mg}$ & Glutamine & $1500 \mathrm{mg}$ \\
\hline Tyrosine & $250 \mathrm{mg}$ & Glycine & $115 \mathrm{mg}$ \\
\hline Threonine & $265 \mathrm{mg}$ & Proline & $630 \mathrm{mg}$ \\
\hline Tryptophan & $25 \mathrm{mg}$ & Serine & $360 \mathrm{mg}$ \\
\hline
\end{tabular}


for 5 days starting the night the exercise was performed. The total intake was $65 \mathrm{~g}$ of milk peptide. Details of the supplement, including its amino acid composition, are presented in Table 1.

\subsection{Data analysis}

Means \pm standard errors (SE) of CK, VAS, and T2 values were compared between the 2 trials (Pep vs. Cont) using 2-way repeated measures ANOVA followed by Tukey's test. In addition, the difference in all measurements between the 2 conditions at each time point (VAS, MRI) and peak value (CK) were statistically analyzed using the paired t-test. values of $<0.05$ were considered statistically significant.

\section{Results}

\subsection{Muscle soreness}

Changes in VAS score through the experimental period were statistically significant in the palpation $(\mathrm{F}=19.9, \mathrm{p}<0.001)$ and extensor conditions $(\mathrm{F}=$ 20.1, $\mathrm{p}<0.001)$.

In the palpation condition, VAS scores increased significantly from day 1 (morning) after exercise

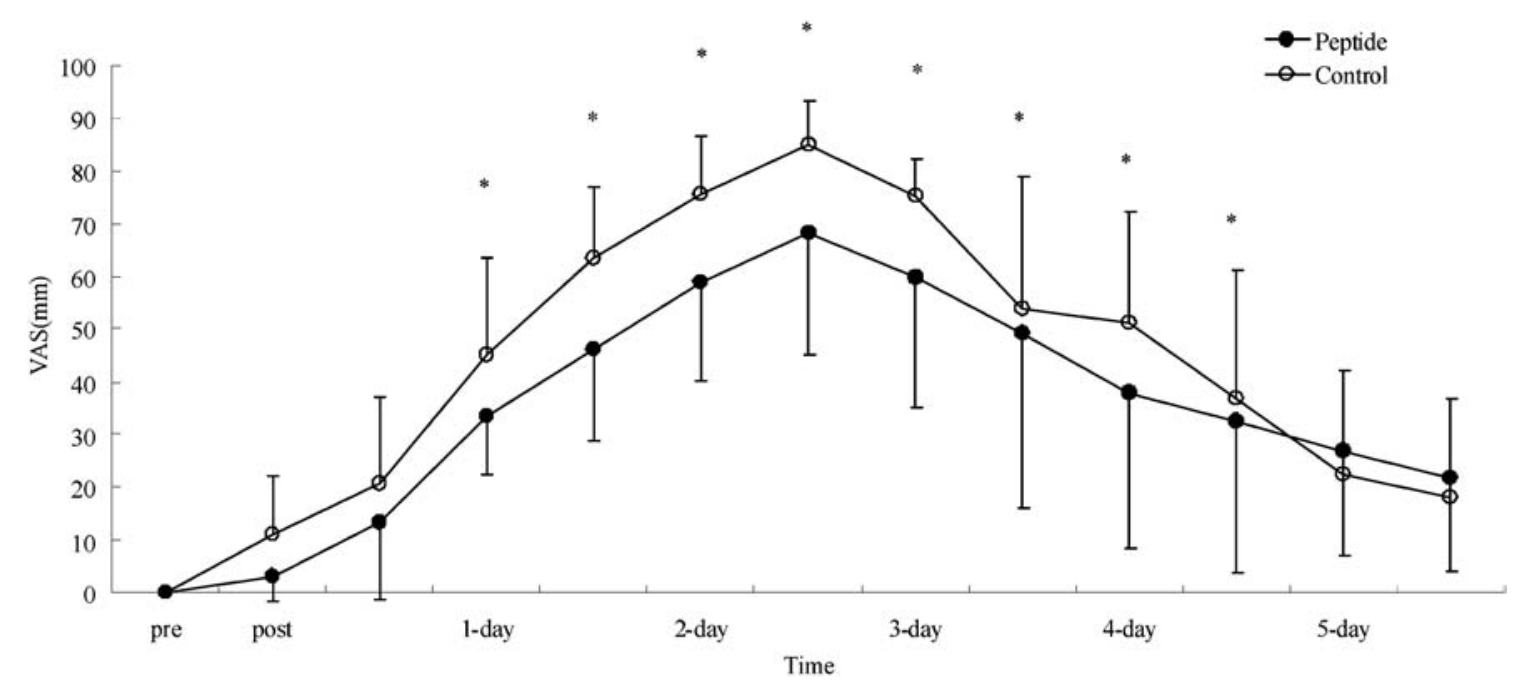

Figure 2a VAS (visual analogue scale) of muscle soreness on palpation. VAS scores ranged from 0 (no pain or soreness) to 10 (worst possible pain and soreness). VAS scores in the peptide trial were significantly lower than those in the control trial $(\mathrm{F}=19.9, \mathrm{p}<0.01) .{ }^{*} \mathrm{p}<0.01$ vs. before exercise.

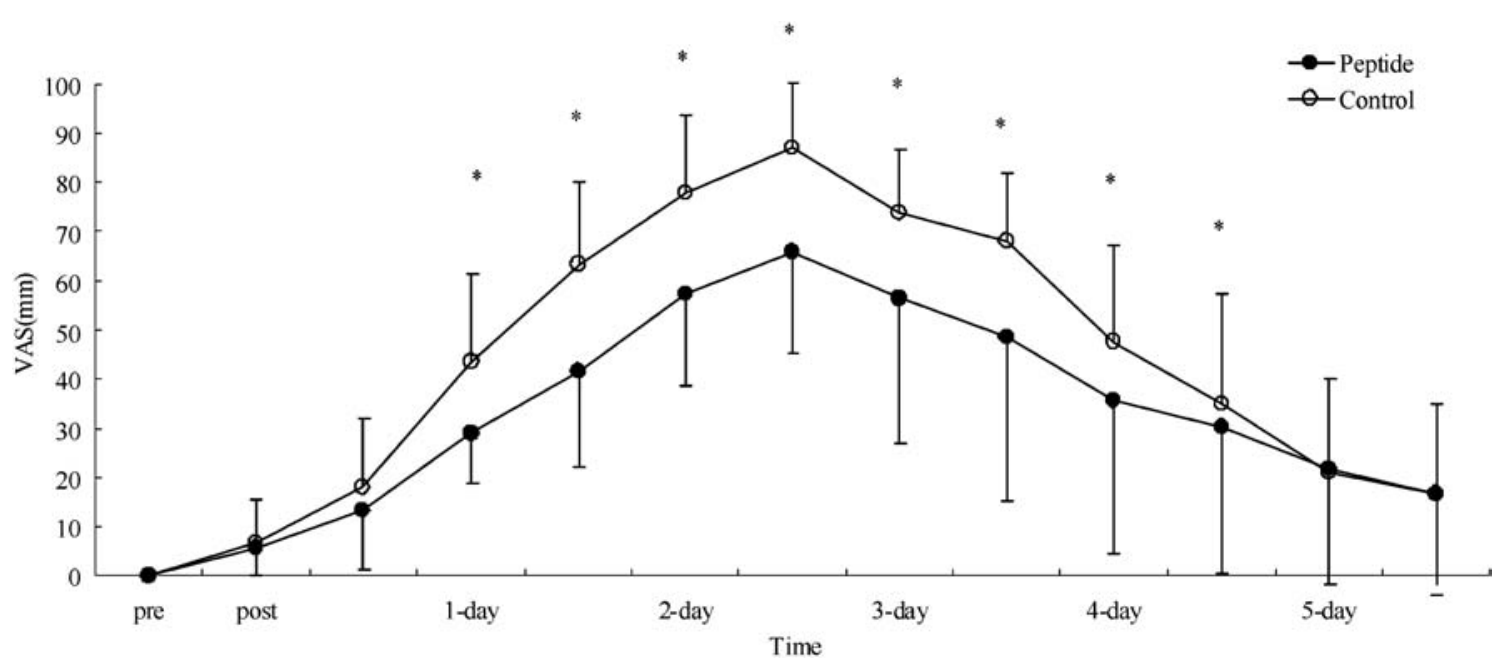

Figure 2b VAS scores for muscle soreness in the extensor. VAS scores ranged from 0 (no pain or soreness) to 10 (worst possible pain and soreness). VAS scores in the peptide trial were significantly lower than those in the control trial $(\mathrm{F}=10.8, \mathrm{p}<0.001) .{ }^{*} \mathrm{p}<0.01$ vs. before exercise. 
(Pep: $33.5 \pm 11.1 \mathrm{~mm}$; Cont: $45.0 \pm 18.5 \mathrm{~mm}$ ) until day 4 (night) after exercise (Pep: $32.5 \pm 28.8 \mathrm{~mm}$; Cont: $36.8 \pm 24.5 \mathrm{~mm}$ ). Overall VAS scores in the peptide trial were lower than those in the control trial $(\mathrm{F}=7.43, \mathrm{p}<0.01)$. The same tendency was observed in the extensor condition [Pep: 13.2 \pm 11.9 $\mathrm{mm}$; Cont: $18.0 \pm 13.9 \mathrm{~mm}$ for day 1 (morning); Pep: $30.3 \pm 30.0 \mathrm{~mm}$; Cont: $35.0 \pm 22.3 \mathrm{~mm}$ for day 4 (night) $(\mathrm{F}=20.08, \mathrm{p}<0.001)]$.

On the whole, VAS scores in the peptide trial were significantly lower than those in the control trial in both palpation $(\mathrm{F}=7.43, \mathrm{p}<0.01)$ and extensor $(\mathrm{F}=$
10.82, $\mathrm{p}<0.01$ ) conditions (Figures 2a, b).

\subsection{Blood CK level}

Blood CK activity increased significantly at 3 days (Pep: $3072 \pm 4047 \mathrm{IU} / \mathrm{L}$; Cont: $5308 \pm 3646 \mathrm{IU} / \mathrm{L}$ ) and 5 days (Pep: $2483 \pm 2438 \mathrm{IU} / \mathrm{L}$; Cont: $4654 \pm$ $4065 \mathrm{IU} / \mathrm{L})$ measurement points after exercise in both trials $(\mathrm{F}=8.92, \mathrm{p}<0.001)$. On the whole, $\mathrm{CK}$ values in the Pep condition tended to be lower than those in the Cont condition $(\mathrm{F}=3.96, \mathrm{p}=0.051)$. The CK value in the Pep condition was markedly

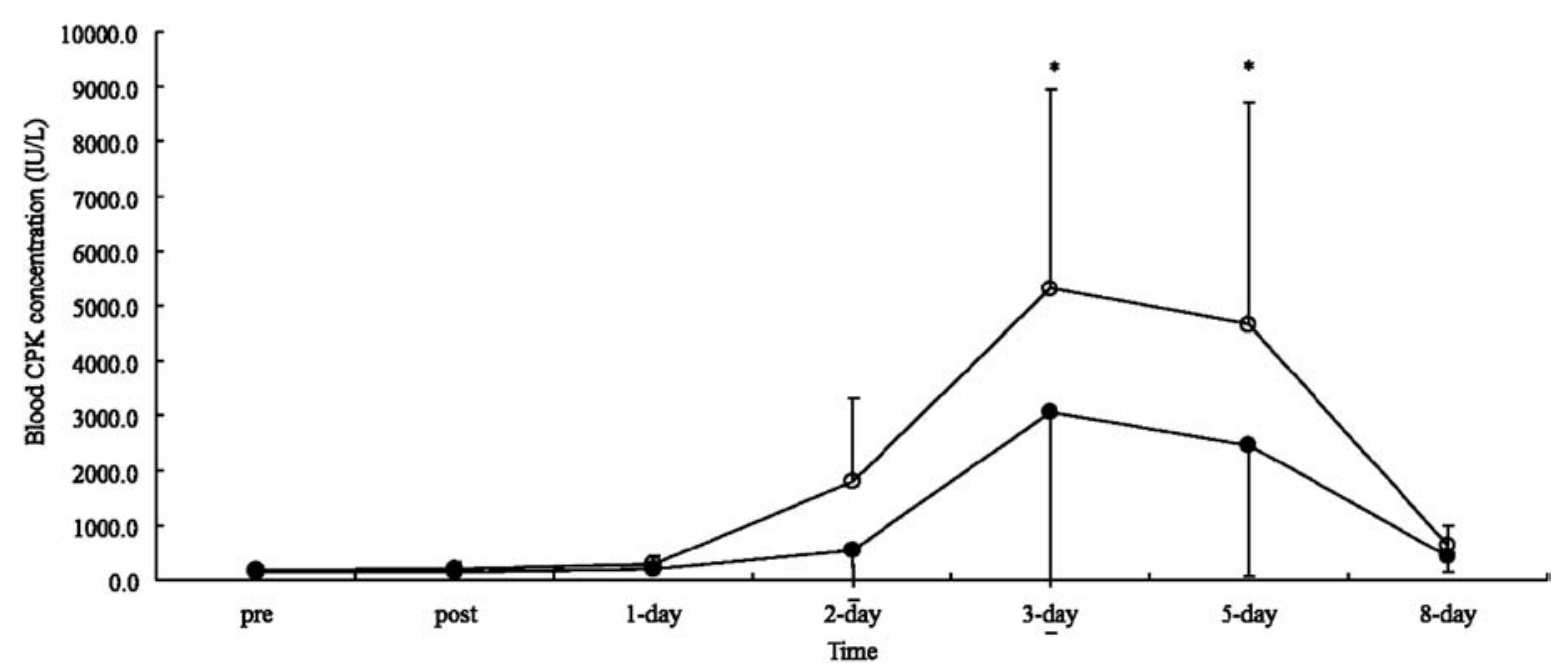

Figure 3a Comparison of blood CK (creatine kinase) levels between the peptide trial and control conditions. No significant difference in CK level was observed between the 2 trials. ${ }^{*} \mathrm{p}<0.01$ vs. before exercise; $+\mathrm{p}<0.05,++$ $\mathrm{p}<0.01$ (Pep vs. Cont).

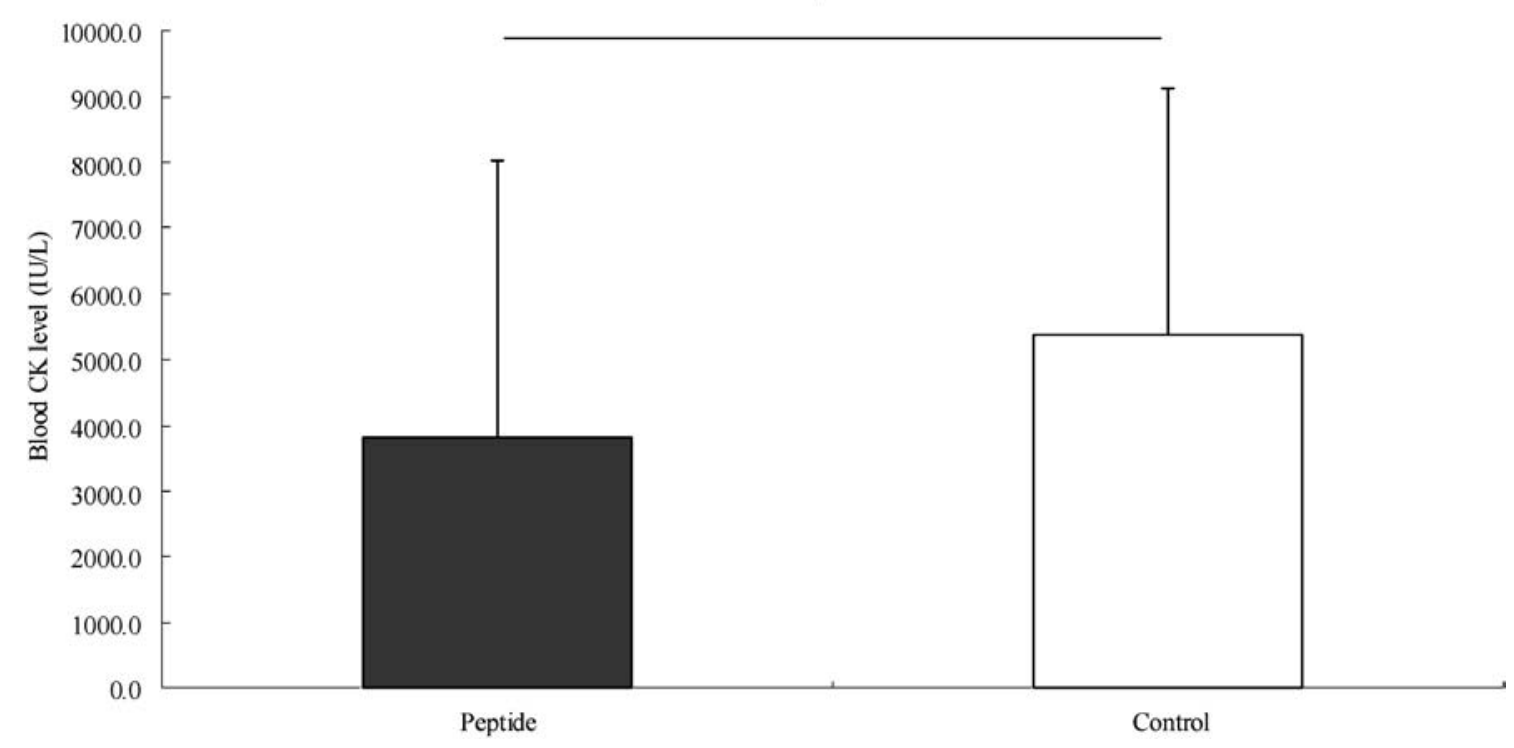

Figure 3b Peak values of blood CK. Peak blood CK values in the peptide trial were significantly lower than those in the control trial. $+\mathrm{p}<0.05$. 
lower at 2 days (Pep vs. Cont: $551 \pm 907 \mathrm{IU} / \mathrm{L}$ vs. $1803 \pm 1532 \mathrm{IU} / \mathrm{L}, \mathrm{p}<0.05), 3$ days $(\mathrm{p}<0.05)$, and 5 days $(\mathrm{p}<0.01)$ measurement points after exercise (Figure 3a).

In this study, peak values of $\mathrm{CK}$ were also compared because of individual differences in timing. As a result, peak CK values in the peptide trial were significantly lower than those in the control trial (3824 $\pm 4188 \mathrm{IU} / \mathrm{L}$ vs. $5362 \pm 3759 \mathrm{IU} / \mathrm{L}, \mathrm{p}<0.05)$ (Figure 3b).

When the peak CK value in the first session (4281 $\pm 4209 \mathrm{IU} / \mathrm{L}$ ) was compared with that of the second session $(4905 \pm 3891 \mathrm{IU} / \mathrm{L})$ without consideration of peptide and control conditions, no significant difference between values was found.

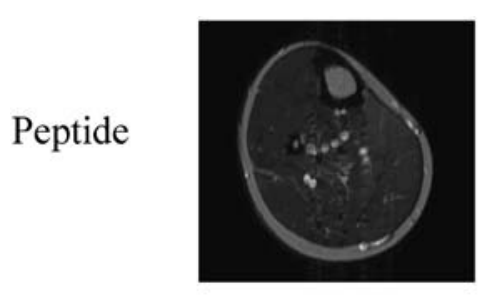

$34.4 \mathrm{~s}$

Before

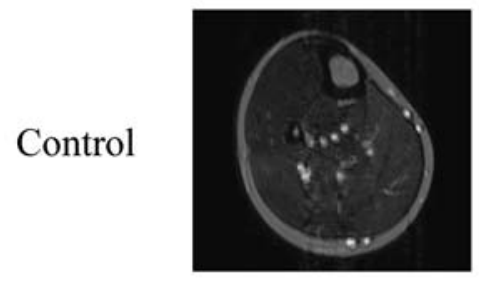

$35.6 \mathrm{~s}$

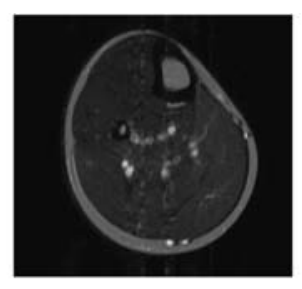

$34.8 \mathrm{~s}$

2 days

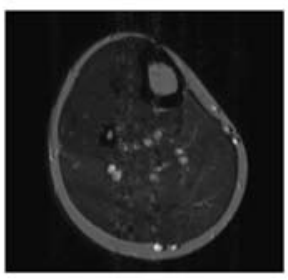

$34.0 \mathrm{~s}$

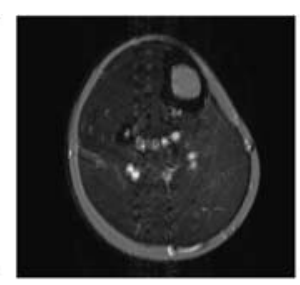

$34.8 \mathrm{~s}$

3 days

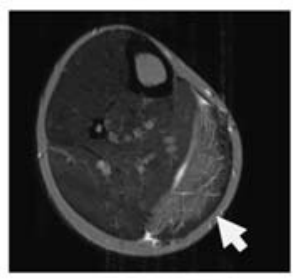

$51.3 \mathrm{~s}$

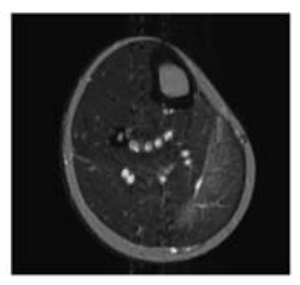

$40.9 \mathrm{~s}$

5 days

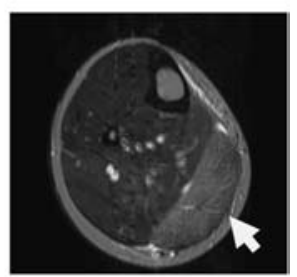

$52.7 \mathrm{~s}$

Figure 4 Typical longitudinal changes in T2-weighted images [(before (pre) and 2, 3, and 5 days after exercise) and resulting $\mathrm{T} 2$ values. In this case, the bilateral calf muscle was predominantly affected by the exercise. Edema in the medial gastrocnemius was remarkable in the control condition (white arrow). ${ }^{*} 1$ day after exercise: Pep. vs. Cont., $35.7 \mathrm{~s}$ vs. $35.2 \mathrm{~s} ; 8$ days after exercise: 43.1 vs. $45.3 \mathrm{~s}$.

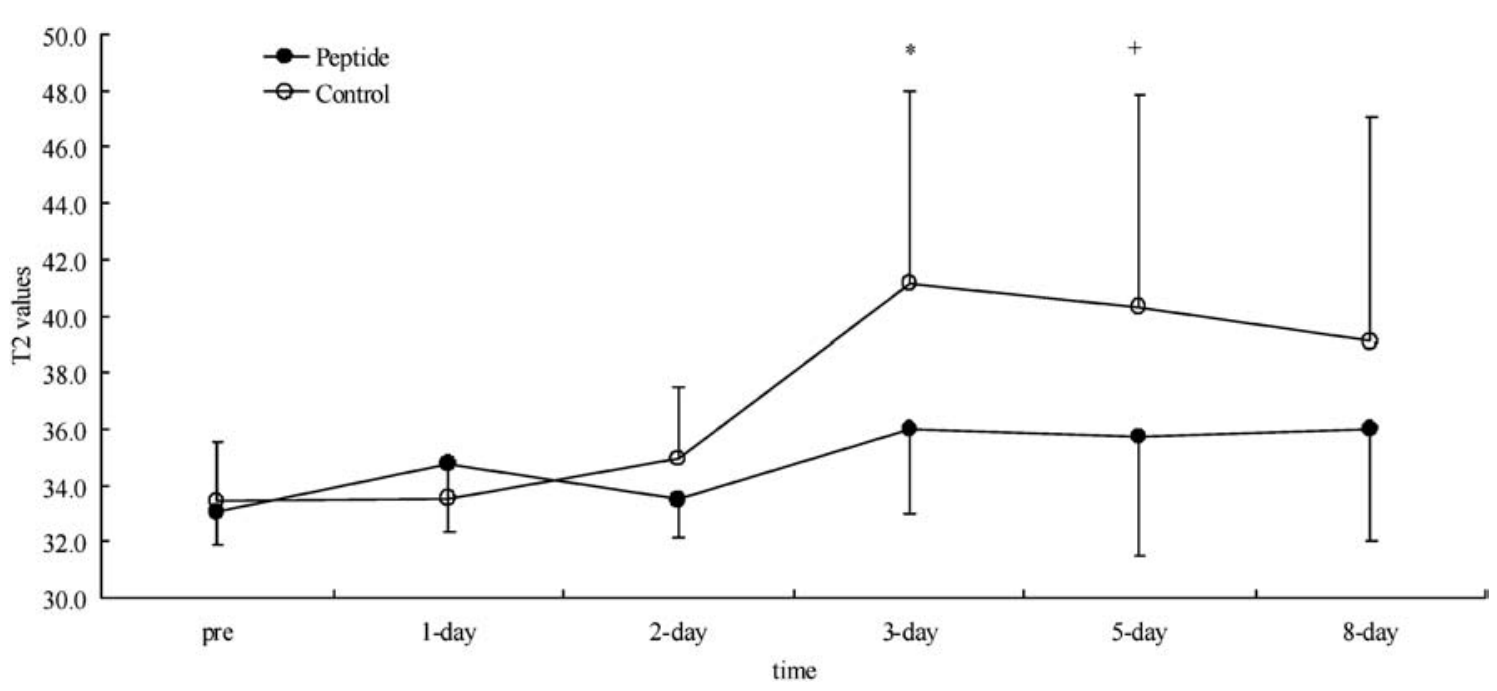

Figure 5 Comparison of $\mathrm{T} 2$ values between the peptide trial and control conditions. T2 values in the peptide trial were significantly lower than those in the control condition. ${ }^{*} \mathrm{p}<0.05$ vs. before exercise; $+\mathrm{p}<0.05$ (Pep vs. Cont). 


\subsection{MRI}

T2 values of the right medial gastrocnemius increased significantly at the 3 -day time point (Pep: $36.0 \pm 1.2 \mathrm{~s}$; Cont: $41.1 \pm 2.8 \mathrm{~s}, \mathrm{p}<0.05)$ after exercise in both conditions (Figure 5). T2 values in the Pep condition were significantly lower than those in the Cont condition $(F=4.76, p<0.05)$, especially 5 days after exercise $(p<0.05)$ (Figures 4 and 5$)$.

In addition, when $\mathrm{T} 2$ values 5 days after exercise were compared between the first $(39.2 \pm 5.2 \mathrm{~s})$ and second $(39.8 \pm 6.7 \mathrm{~s})$ sessions regardless of peptide and control conditions, no significant difference was observed between values.

\section{Discussion}

This study investigated the effect of milk peptide intake on eccentric exercise-induced muscle damage and DOMS by evaluation of blood CK levels, MRI $\mathrm{T} 2$ values, and VAS scores. The main result was that milk peptide intake decreased peak CK levels, MRI T2 values, and VAS scores throughout the experimental period (from before exercise to 5 days after exercise). These findings indicated that milk peptide intake may attenuate muscle damage and muscle soreness following eccentric exercise.

Muscle damage has been implicated in muscle protein degradation (Fielding et al., 1991). Intake of protein sources, such as protein, peptide, and amino acid, increases amino acid availability and changes the body's protein metabolism. In a previous study, protein metabolism increased with protein ingestion following resistance exercise (Tipton et al., 2004). An increase in protein metabolism may enhance recovery from muscle damage. Several other studies have examined the effects of intake of various protein sources on muscle damage and DOMS following eccentric exercise (Cockburn et al., 2008; Etheridge et al., 2008; Nosaka et al., 2006; Shimomura et al., 2006; White et al., 2008). However, their results are inconsistent. Possible reasons for discrepancies include differences in exercise modality (i.e., box stepping, eccentric exercise, downhill running), intensity (endurance exercise or heavy-load eccentric exercise), loaded region (upper extremity or lower extremity), and supplementation protocols (amount, timing, and frequency) (Cockburn et al., 2008; Etheridge et al., 2008; Nosaka et al., 2006; Shimomura et al., 2006; White et al.,
2008).

In this study, milk peptide intake may have decreased muscle damage and soreness following eccentric exercise. Possible factors influencing this result include the characteristics of the milk peptide and the frequency of supplementation. In a previous study, no significant effect of protein intake before or after eccentric exercise on indices of muscle damage was found following eccentric exercise (White et al., 2008). White et al. (2008) concluded that the effects of delaying ingestion of intact proteins required examination. In this study, peptide was utilized, as it is known to have better digestive and absorption qualities than protein, and thus may help the body synthesize protein after exercise (Cockburn et al., 2008; Mikami et al., 1998). Attenuation of muscle damage and DOMS may therefore be accomplished by decreasing muscle protein degradation efficiently. These different characteristics of digestion and absorption between protein and peptide may explain the results observed here.

Subjects ingested milk peptide 13 times throughout this study, thereby decreasing the number of markers of muscle damage and muscle soreness. Nosaka et al. (2006) reported that ingestion of 12 kinds of amino acid mixture for 4 days (10 times) decreased markers of muscle damage (plasma CK level and myoglobin level) and muscle soreness on palpation (VAS) following endurance exercise of elbow flexors. They concluded that this supplementation regimen decreased both muscle damage and muscle soreness. Therefore chronic supplementation may speed recovery as indicated by systemic markers of cellular damage or stress and perceptions of muscle soreness. Further studies are needed to determine the impact of the timing and frequency of peptide intake on exercise-induced muscle damage.

Moreover, in previous studies examining the effect of protein or amino acid intake on exercise-induced muscle damage, subjects performed light exercise, which induced only small increases in blood CK of $<1,500 \mathrm{IU} / \mathrm{L}$ (Braun et al., 2005; Cockburn et al., 2008; Etheridge et al., 2008; Nosaka et al., 2006; Shimomura et al., 2006; Tipton et al., 2004; White et al., 2008). Thus, the effect of supplementation on muscle damage following high-intensity exercise was uncertain. However, in this study, subjects performed the calf-raise exercise loaded with weight equal to their body weight, inducing increases in blood CK levels from 1,000-12,000 IU/L. This high- 
intensity exercise caused greater muscle damage than was observed in previous studies. Despite the magnitude of damage, peak blood CK levels, MRI T2 values, and VAS scores in the peptide trial were significantly lower than those in the control condition. This result may inform management of DOMS following heavy-load eccentric exercise such as that experienced during sports activities.

The current study has some limitations. Similar to in previous studies, this study speculated a relationship between muscle damage following eccentric muscle action and changes in muscle protein metabolism. Recent studies have reported that amino acids, especially leucine, may enhance protein synthesis with modulating mTOR-dependent signaling through TSC1-TSC2, G $\beta \mathrm{L}$, Raptor, and/or Rheb (Bolster et al., 2004). However, although the findings of this study may be explained by leucinedependent protein synthesis enhancement, the mechanisms by which milk peptide intake improves recovery of muscle damage and muscle soreness have yet to be fully elucidated. Further studies focusing on the role of increased amino acid (especially leucine) availability on myofibrillar protein synthesis must be conducted.

The "repeated bout effect" must also be taken into consideration. Previous studies reported that a single session of eccentric exercise can produce an adaptation such that the muscle is more resistant to damage during subsequent bouts of exercise (Clarkson et al., 1992; Mchugh et al., 1999). This protective effect may last more than 6 weeks (Clarkson et al., 1992). Although the repeated bout effect should not be ignored, this protective effect was offset and minimized in the current study by its crossover design. For example, peak CK levels in the second session were very similar to those in the first session, while the "repeated bout effect"' decreased CK levels to $<10 \%$ of those in the first session in another study (Clarkson et al., 1992). Finally, a control condition was utilized in this study instead of placebo. This protocol may have caused the researchers (subjects) not to manage (perform) eccentric exercise with their best effort in the control condition. To eliminate this potential bias, subjects were urged to exert maximum effort in both conditions. In addition, exercise management, peptide administration, MRI scanning, and CK measurement were all performed by different researchers. Future research may verify the findings of this study using a placebo instead of a control condition.

In conclusion, the present study showed that milk peptide intake was effective in decreasing peak blood CK levels, MRI T2 values, and VAS scores following performance of an eccentric calf-raise exercise when the supplement was ingested $1 \mathrm{~h}$ before exercise and immediately after exercise, and twice a day for 5 days starting the night of the first session. These results suggest that milk peptide intake may enhance recovery from muscle damage and DOMS after eccentric exercise.

\section{References}

Armstrong, R. B. (1984). Mechanisms of exercise-induced delayed onset muscular soreness: a brief review. Med. Sci. Sports Exerc., 16: 529-538.

Bolster, D. R., Jefferson, L. S., and Kimball, S. R. (2004). Regulation of protein synthesis associated with skeletal muscle hypertrophy by insulin-, amino acid- and exercise-induced signalling. Proc. Nutr. Soc., 63: 351-356.

Braun, W. A., Flynn, M. G, Armstrong, W. J., and Jacks, D. D. (2005). The effects of chondroitin sulfate supplementation on indices of muscle damage induced by eccentric arm exercise. J. Sports Med. Phys. Fitness, 45: 553-560.

Cheung, K., Hume, P., and Maxwell, L. (2003). Delayed onset muscle soreness: treatment strategies and performance factors. Sports Med., 33: 145-164.

Clarkson, P. M., Nosaka, K., and Braun, B. (1992). Muscle function after exercise-induced muscle damage and rapid adaptation. Med. Sci. Sports Exerc., 24: 512-520.

Clarkson, P. M., and Hubal, M. J. (2002). Exercise-induced muscle damage in humans. Am. J. Phys. Med. Rehabil., 81: S52-S69.

Cleak, M. J., and Eston, R. G. (1992). Delayed onset muscle soreness: mechanisms and management. J. Sport Sci., 10: 325-341.

Close, G. L., Ashton, T., Cable, T., Doran, D., Holloway, C., McArdle, F., and MacLaren, D. P. (2006). Ascorbic acid supplementation does not attenuate post-exercise muscle soreness following muscle-damaging exercise but may delay the recovery process. Brit. J. Nutr., 95: 976-981.

Cockburn, E., Hayes, P. R., French, D. N., Stevenson, E., and St Clair Gibson, A. (2008). Acute milk-based protein-CHO supplementation attenuates exercise-induced muscle damage. Appl. Physiol. Nutr. Metab., 33: 775-783.

Coombes, J. S., and McNaughton, L. R. (2000). Effects of branched-chain amino acid supplementation on serum creatine kinase and lactate dehydrogenase after prolonged exercise. J. Sports Med. Phys. Fitness, 40: 240-246.

Etheridge, T., Philp, A., and Watt, P. W. (2008). A single protein meal increases recovery of muscle function following an acute eccentric exercise bout. Appl. Physiol. Nutr. Metab., 33: 483-488.

Fielding, R. A., Meredith, C. N., O’Reilly, K. P., Frontera, W. R., Cannon, J. G., and Evans W. J. (1991). Enhanced protein breakdown after eccentric exercise in young and older men. J. Appl. Physiol., 71: 674-679.

Harrison, A. J., and Gaffney, S. D. (2004). Effects of muscle damage on stretch-shortening cycle function and muscle stiff- 
ness control. J. Strength Cond. Res., 18: 771-776.

Howatson, G., and van Someren, K. A. (2008). The prevention and treatment of exercise-induced muscle damage. Sports Med., 38: 483-503.

Kraemer, W. J., Ratamess, N. A., Volek, J. S., Hakkinen, K., Rubin, M. R., French, D. N., Gomez, A. L., McGuigan, M. R., Scheett, T. P., Newton, R. U., Spiering, B. A., Izquierdo, M., and Dioguardi, F. S. (2006). The effects of amino acid supplementation on hormonal responses to resistance training overreaching. Metabolism, 55: 282-291.

LeBlanc, A. D., Jaweed, M., and Evans, H. (1993). Evaluation of muscle injury using magnetic resonance imaging. Clin. J. Sports Med., 3: 26-30.

Lenn, J., Uhl, T., Mattacola, C., Boissonneault, G., Yates, J., Ibrahim, W., and Bruckner, G. (2002). The effects of fish oil and isoflavones on delayed onset muscle soreness. Med. Sci. Sports Exerc., 34: 1605-1613.

Mikami, T., Ito, A., and Yoshin, Y. (1998). Effect of administration of peptides on protein synthesis and breakdown in skeletal muscle and liver after strenuous exercise. Descente Sports Sci., 19: 183-190. (Japanese)

Miller, P. C., Bailey, S. P., Barnes, M.E., Derr, S. J., and Hall, E. E. (2004). The effects of protease supplementation on skeletal muscle function and DOMS following downhill running. J. Sport Sci., 22: 365-372.

McHugh, M. P., Connolly, D. A., Eston, R. G., and Gleim, G. W. (1999). Exercise-induced muscle damage and potential mechanisms for the repeated bout effect. Sports Med., 27: 157-170.

Nosaka, K., and Clarkson, P. M. (1996). Variability in serum creatine kinase response after eccentric exercise of the elbow flexors. Int. J. Sports Med., 17: 120-127.

Nosaka, K., Sacco, P., and Mawatari, K. (2006). Effects of amino acid supplementation on muscle soreness and damage. Int. J. Sport Nutr. Exerc. Metab., 16: 620-635.

Shimomura, Y., Yamamoto, Y., Bajotto, G., Sato, J., Murakami, T., Shimomura, N., Kobayashi, H., and Mawatari, K. (2006). Nutraceutical effects of branched-chain amino acids on skeletal muscle. J. Nutr., 136, 529S-532S.

Sugita, M., Ohtani, M., Ishii, N., Maruyama, K., and Kobayashi, K. (2003). Effect of a selected amino acid mixture on the recovery from muscle fatigue during and after eccentric contraction exercise training. Biosci. Biotechnol. Biochem., 67: 372-375.

Tipton, K. D., Elliott, T. A., Cree, M. G., Wolf, S. E., Sanford, A. P., and Wolfe, R. R. (2004). Ingestion of casein and whey proteins result in muscle anabolism after resistance exercise. Med. Sci. Sports Exerc., 36: 2073-2081.

Twist, C., and Eston, R. (2005). The effects of exercise-induced muscle damage on maximal intensity intermittent exercise performance. Eur. J. Appl. Physiol., 94: 652-658.

White, J. P., Wilson, J. M., Austin, K. G., Greer, B. K., St John, N., and Panton, L. B. (2008). Effect of carbohydrateprotein supplement timing on acute exercise-induced muscle damage. J. Int. Soc. Sports Nutr., 5: 5.

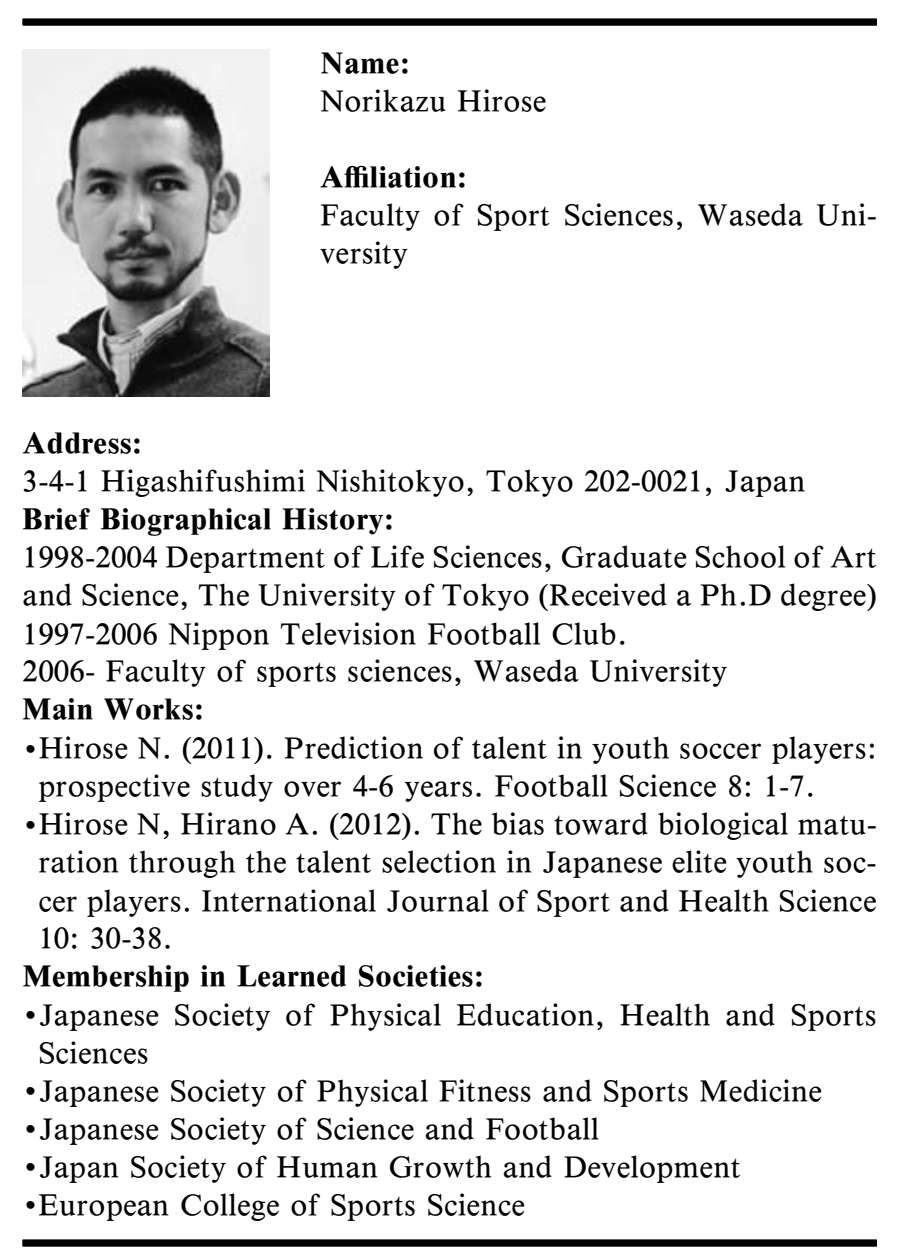

